\title{
ERYTHROPOIESIS AFTER NONMYELOABLATIVE STEM-CELL TRANSPLANTATION IS NOT IMPAIRED BY INADEQUATE ERYTHROPOIETIN PRODUCTION AS OBSERVED AFTER CONVENTIONAL ALLOGENEIC TRANSPLANTATION
}

\author{
F. BARON, ${ }^{1}$ G. Fillet, ${ }^{1}$ AND Y. BeGuin ${ }^{1,2}$
}

\begin{abstract}
Background. It is now well established that after conventional allogeneic hematopoietic stem-cell transplantation (HSCT), erythropoietic recovery is impaired because erythropoietin (Epo) production remains inadequate for prolonged periods of time. However, erythropoietic reconstitution after nonmyeloablative SCT (NMSCT) has never been characterized.

Methods. Twelve patients received a nonmyeloablative conditioning regimen consisting of $2 \mathrm{~Gy}$ total body irradiation (TBI) alone $(n=6), 2$ Gy TBI and fludarabine $(n=3)$, or cyclophosphamide and fludarabine $(n=3)$, followed by transplantation of allogeneic peripheral blood stem cells. Graft-versus-host-disease (GvHD) prophylaxis was carried out with mycophenolate mofetil (from day -1 to day 28 ) plus cyclosporine (from day -1 to day 120 or longer in case of chronic GvHD). Erythropoiesis was quantitated by soluble transferrin receptor (sTfR) levels, and the adequacy of Epo production was evaluated by the observed-to-predicted Epo ratio (O/P Epo).

Results. Mean sTfR levels decreased following the conditioning regimen but remained well within the normal range throughout the posttransplant period. The O/P Epo ratio presented an initial surge quite similar to that observed after conventional conditioning. Thereafter, the O/P Epo ratio normalized rapidly, and Epo levels remained adequate during the whole observation period.
\end{abstract}

Conclusion. Contrarily to what is observed after myeloablative transplant, Epo levels remained adequate after NMSCT, resulting in normal erythropoiesis. These results suggest that the administration of erythropoietin therapy (rHuEpo) could be less effective after NMSCT than after conventional allogeneic transplant.

Allogeneic hematopoietic stem-cell transplantation (HSCT) is an effective treatment for selected hematologic malignancies $(1,2)$. Its curative potential is in part achieved through an immune-mediated destruction of malignant cells by donor lymphocytes termed the graft-versus-leukemia (GVL) effect (2-7). However, because of its toxicity, conventional allogeneic HSCT is restricted to younger and fitter patients $(8)$. Therefore, several groups have developed the concept of nonmyeloablative stem-cell transplantation (NMSCT), in which the main mechanism of tumor eradica-

\footnotetext{
${ }^{1}$ Department of Medicine, Division of Haematology, University of Liège, Liège, Belgium.

${ }^{2}$ Address correspondence to: Dr. Yves Beguin, University of Liège, Department of Hematology, CHU Sart-Tilman, 4000 Liège, Belgium. E-mail: yves.beguin@chu.ulg.ac.be.

Received 9 May 2002. Accepted 11 July 2002.

DOI: 10.1097/01.TP.0000038728.65545.FE
}

tion is shifted from high-dose cytotoxic agents to the GVL effect $(9,10)$. After extensive preclinical studies (11-15), the Seattle team developed a nonmyeloablative HSCT approach combining 2 Gy total body irradiation (TBI) $\pm 90 \mathrm{mg} / \mathrm{m}^{2}$ fludarabine as a conditioning regimen and postgrafting immunosuppression with cyclosporine (CsA) and mycophenolate mofetil (MMF). This approach was recently shown to be feasible even in elderly or sick patients who were ineligible for a conventional transplant $(9,16)$. Because of the mild conditioning regimen given and the use of peripheral blood stem cells (PBSC) as the source of hematopoietic stem cells, posttransplant myelosuppression remained modest and transient $(9,16)$. Moreover, the Seattle team recently demonstrated that both red-blood-cell (RBC) and platelet transfusion requirements were reduced in NMSCT compared with conventional PBSC transplant recipients (10).

Erythropoietin (Epo) is the critical regulatory factor of erythropoiesis (17). In patients with normal kidney function, serum Epo levels increase exponentially when an anemia develops. After high-dose chemotherapy, serum Epo levels first rapidly increase to disproportionately high levels for 1 to 3 weeks, with peak values usually observed in the first week after the conditioning regimen (18-27). However, after allogeneic SCT, the Epo response to anemia then generally becomes impaired, resulting in inappropriately low Epo levels for the degree of anemia and prolonged anemia $(21,24)$. This is specific for allogeneic transplants because serum Epo levels remain adequate throughout the posttransplant course in recipients of an autologous marrow or PBSC transplant (19, $20,22,23,25-28$ ). This defect in Epo production has been attributed to the use of cyclosporine (29), which does not affect the expression of the Epo gene but causes an inhibition of Epo secretion (30). However, other factors such as graftversus-host disease (GvHD) $(20,24,28,31)$ or cytomegalovirus $(\mathrm{CMV})$ infection $(20,28)$ may also contribute to it. On the basis of these findings, it is not surprising that erythropoietin therapy (rHuEpo) shows some efficacy in the early posttransplant period after allogeneic $(32,33)$ but not autologous transplantation $(32,33)$, but is remarkably efficient when it is started after day 35 postallogeneic transplantation (34).

However, erythropoietic recovery after a nonmyeloablative transplant has not been well characterized, and it is not known whether rHuEpo could enhance erythroid function in this setting. In this study, we examined the reconstitution of erythropoiesis in 12 recipients of a nonmyeloablative transplant (NMSCT group, $n=12$ ). Results were compared with a group of conventional bone-marrow-transplant (BMT) recipients previously reported (BMT group, $\mathrm{n}=47)(25)$ and with a group of patients undergoing a standard myeloablative PBSC transplant (PBSC group, $\mathrm{n}=6$ ). 


\section{PATIENTS AND METHODS}

\section{Patients and Donors}

We studied 12 patients (Table 1) receiving a PBSC transplant after a nonmyeloablative conditioning regimen (16). Written informed consent was obtained from patients to draw blood samples for the study. Conditioning (Table 1) consisted of 2 Gy single dose TBI alone on day $0(n=6)$. For patients not heavily pretreated or for unrelated transplants, TBI was combined with $30 \mathrm{mg} / \mathrm{m}^{2} /$ day fludarabine for 3 days $(n=3)$. The first patient was an exception to this rule because the high rejection rate in chronic myeloid leukemia patients with the original Seattle protocol was not yet published when she was treated. Finally, 3 patients received a combination of fludarabine and cyclophosphamide at $1 \mathrm{~g} / \mathrm{m}^{2}$ per day for 3 days (Fluda-Cy) because they had previously received 12 Gy TBI as conditioning regimen for an autotransplant (Table 1). Posttransplant immunosuppression was carried out orally with cyclosporine (CsA twice daily dose adjusted to achieve whole blood levels in the range

TABle 1. Patient characteristics

\begin{tabular}{|c|c|c|}
\hline Characteristic & $\begin{array}{l}\text { NMSCT } \\
(\mathrm{n}=12)\end{array}$ & $\begin{array}{l}\text { PBSC } \\
(\mathrm{n}=6)\end{array}$ \\
\hline Median age (years) & 58 & 38 \\
\hline $\operatorname{Sex}(M / F)$ & $10 / 2$ & $5 / 1$ \\
\hline \multicolumn{3}{|l|}{ Disease } \\
\hline Lymphoma & 6 & 1 \\
\hline Acute leukemia & 2 & 3 \\
\hline Chronic myeloid leukemia & 2 & 1 \\
\hline Renal-cell carcinoma & 1 & 0 \\
\hline Chronic lymphocytic leukemia & 1 & 0 \\
\hline Aplastic anemia & 0 & 1 \\
\hline \multicolumn{3}{|l|}{ Disease status } \\
\hline Untreated & 2 & 3 \\
\hline CR1 or CR2 & 4 & 3 \\
\hline More advanced & 6 & 0 \\
\hline \multicolumn{3}{|l|}{ Conditioning Myeloablative } \\
\hline TBI-based & 0 & 4 \\
\hline Other & 0 & 2 \\
\hline \multicolumn{3}{|l|}{ Nonmyeloablative } \\
\hline 2 Gy TBI & 6 & 0 \\
\hline Fludarabine and 2 Gy TBI & 3 & 0 \\
\hline Fludarabine and Cyclophosphamide & 3 & 0 \\
\hline \multicolumn{3}{|l|}{ Donor } \\
\hline Sibling, HLA identical & 7 & 5 \\
\hline Sibling, 1 mismatch & 3 & 1 \\
\hline Unrelated, HLA identical & 2 & 0 \\
\hline \multicolumn{3}{|l|}{ Source of stem cells } \\
\hline PBSC & 12 & 6 \\
\hline $\mathrm{BM}$ & 0 & 0 \\
\hline \multicolumn{3}{|l|}{ Major ABO incompatibility } \\
\hline Yes & 4 & 3 \\
\hline No & 8 & 3 \\
\hline \multicolumn{3}{|l|}{ CMV status (donor-recipient) } \\
\hline Negative-negative & 3 & 4 \\
\hline Other & 9 & 2 \\
\hline \multicolumn{3}{|l|}{ GvHD prophylaxis } \\
\hline $\mathrm{CyA}$ and $\mathrm{MMF}$ & 12 & 0 \\
\hline CyA and MTX & 0 & 6 \\
\hline \multicolumn{3}{|l|}{ Grade II-IV acute GvHD } \\
\hline Yes & 4 & 4 \\
\hline No & 8 & 2 \\
\hline
\end{tabular}

NMSCT, nonmyeloablative stem-cell transplantation; PBSC, peripheral blood stem cells; TBI, total body irradiation; HLA, human leukocyle antigen; BM, bone marrow; GMV, cytomegalovirus; GvHD, graft-versus-host disease; MMF, mycophenolate mofetil; MTX, methotrexate. of $300-400 \mathrm{ng} / \mathrm{mL}$ from day -1 to day 120 or longer in case of alternative donor or chronic GvHD) and MMF (15 mg/kg twice daily from day -1 to day 28). The trigger values for $\mathrm{RBC}$ and platelet transfusion were $8.0 \mathrm{~g} / \mathrm{dL}$ and $15 \times 10^{9} / \mathrm{L}$, respectively. Granulocyte (G)-CSF ( $5 \mu \mathrm{g} / \mathrm{kg}$ per day) was administered when the granulocyte count was below $1.0 \times 10^{9} / \mathrm{L}$. The diagnosis and grading of acute and chronic GvHD was established as previously reported (16). Polymerase chain reaction (PCR) for CMV was performed weekly until day 100 and every 2 to 4 weeks thereafter. Patients with a positive PCR received preemptive ganciclovir for a minimum of 4 weeks and generally up to day 100.

\section{Laboratory Analyses}

CsA levels were measured by chromatography. Complete blood counts were determined in a Technicon H2 cell counter (Bayer, Tarrytown, NJ). Serum Epo levels were measured by a commercially available radioimmunoassay (Incstar Corp., Stillwater, MN). On the basis of regression equations obtained in appropriate reference subjects between hematocrit (Hct) on the one hand and log (Epo) on the other, predicted log (Epo) values were derived for each Hct, and O/P ratios of observed-predicted Epo values were calculated (31). The mean ( \pm standard deviation) Epo O/P ratio in a cohort of 31 normal donors was $1.03 \pm 0.08$. Serum-soluble transferrin receptor (sTfR), a quantitative measure of total erythropoietic activity, was measured by a commercially available ELISA (R\&D, Minneapolis, MN). Normal values range from 3,000 to $7,000 \mu \mathrm{g} / \mathrm{L}$.

\section{Statistical Analysis}

Unpaired Student's $t$ tests were used to compare biologic variables in two groups. Welsh's correction was used in case of unequal variance. The probability of GvHD and CMV reactivation were studied by life-table analyses, and Wilcoxon rank tests were used for comparisons between groups. Statistical analyses were carried out with Graphpad Prism (Graphpad Software, San Diego, CA).

\section{RESULTS \\ Clinical Data}

Mean CsA blood levels were $416 \pm 143 \mathrm{ng} / \mathrm{mL}$ on day 14 , $308 \pm 116 \mathrm{ng} / \mathrm{mL}$ on day 42 , and $208 \pm 66 \mathrm{ng} / \mathrm{mL}$ on day 100 , respectively (Fig. 1). The actuarial 150-day incidence of grade I-IV (II-IV) acute GvHD was 41\% (25). The actuarial 150-day incidence of CMV reactivation was $58 \%$.

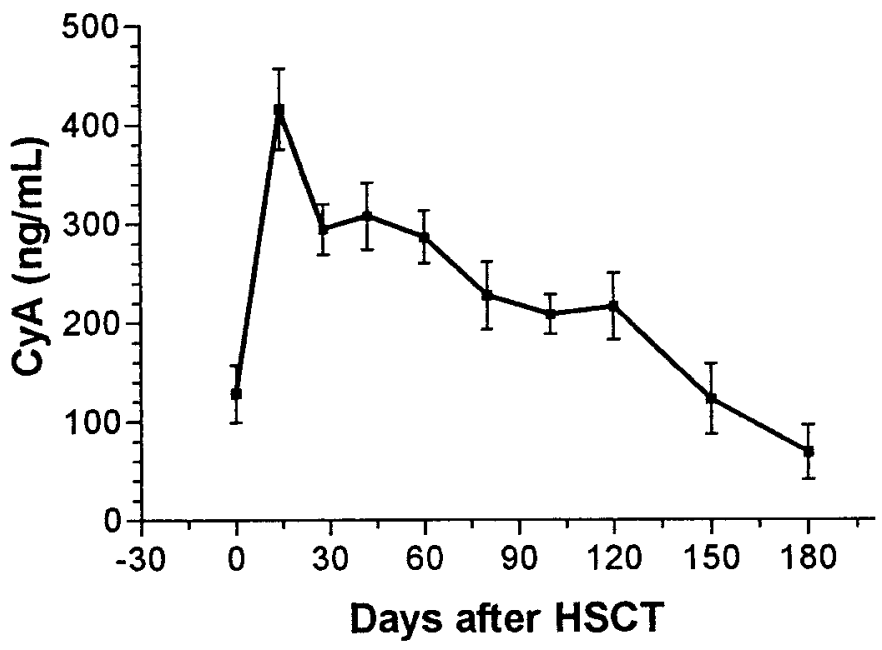

FIGURE 1. Cyclosporine blood levels in the nonmyeloablative stem-cell transplantation (NMSCT) group. HSCT, hematopoietic stem cell transplantation. 


\section{Erythropoietic Activity}

NMSCT recipients were compared with conventional BMT recipients. There was little difference in Hemoglobin $(\mathrm{Hb})$ levels after transplantation because patients in the BMT group were supported by RBC transfusions when their $\mathrm{Hb}$ fell below $10 \mathrm{~g} / \mathrm{dL}$ (many transfusions), but patients in the NMSCT group maintained better $\mathrm{Hb}$ levels, with few transfusions when the $\mathrm{Hb}$ was less than $8 \mathrm{~g} / \mathrm{dL}$ (Fig. 2). After conventional BMT, sTfR levels decreased sharply after the conditioning regimen to a minimum of $2040 \pm 740$ on day 14 then increased up to day 60 but decreased again thereafter $(P<0.02$ between days 60 and 150) (Fig. 3). The evolution was very similar in the conventional PBSC group with a nadir of $1000 \pm 350 \mu \mathrm{g} / \mathrm{L}$ on day 14 followed by a recovery through day 80 and a secondary decrease thereafter. In the NMSCT group, sTfR levels were $6520 \pm 2120 \mu \mathrm{g} / \mathrm{L}$ before conditioning and decreased significantly $(P=0.007)$ to a minimum of $4000 \pm 1710 \mu \mathrm{g} / \mathrm{L}$ on day 10 but remained consistently above $5000 \mu \mathrm{g} / \mathrm{L}$ thereafter (Fig. 3). The initial sTfR decrement was significantly smaller than after conventional HSCT, and sTfR values never fell below the normal range.

\section{Serum Erythropoietin Levels}

After NMSCT, serum Epo levels peaked on day 0 with a mean O/P Epo of $1.12 \pm 0.11(P=0.0057$ compared with $\mathrm{O} / \mathrm{P}$ Epo in 31 healthy donors), which was very similar to the $\mathrm{O} / \mathrm{P}$ Epo of 1.11 \pm 0.20 after conventional BMT (Fig. 4). Although O/P Epo after conventional BMT between days 14 and 180 were significantly lower than in normal subjects $(P<0.05$ to $P<0.001)$ and significantly decreased compared with pretransplant values $(P<0.02$ to $P<0.001)$, Epo production was adequate throughout the posttransplant course after NMSCT (Fig. 4). Moreover, O/P Epo ratio remained significantly higher in the NMSCT group compared with the BMT group from day 28 to day 180 (Fig. 4). Indeed, the average O/P Epo of all samples obtained between days 14 and 180 in all NMSCT recipients $(0.99 \pm 0.19, \mathrm{n}=105)$ did not significantly differ from the O/P Epo of normal subject (1.03 \pm 0.08 ,

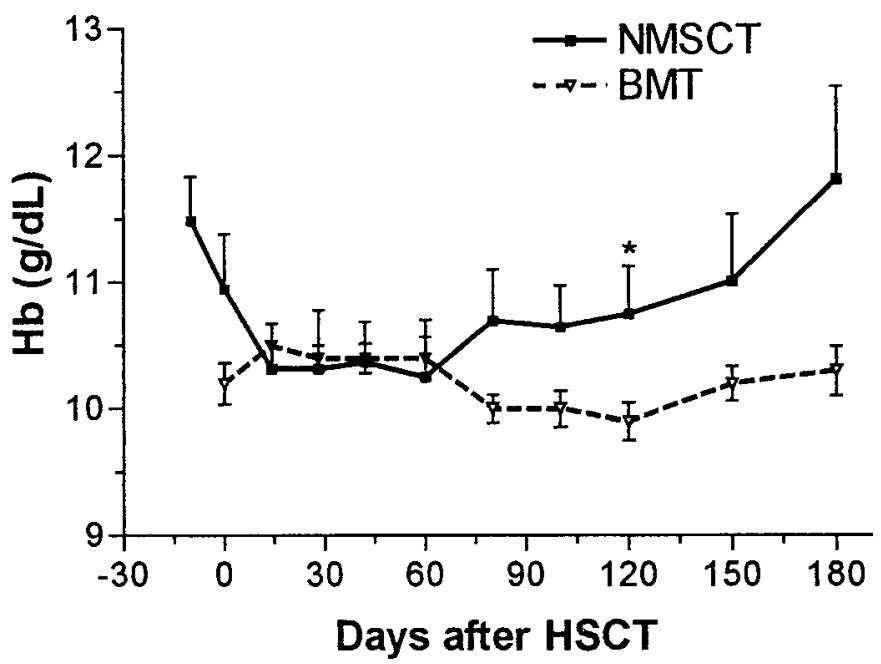

Figure 2. Hemoglobin (Hb) levels (mean \pm SEM) after conventional bone marrow transplant (BMT) or NMSCT. $P$ values are given for comparisons between the two groups, $* P<0.05$.

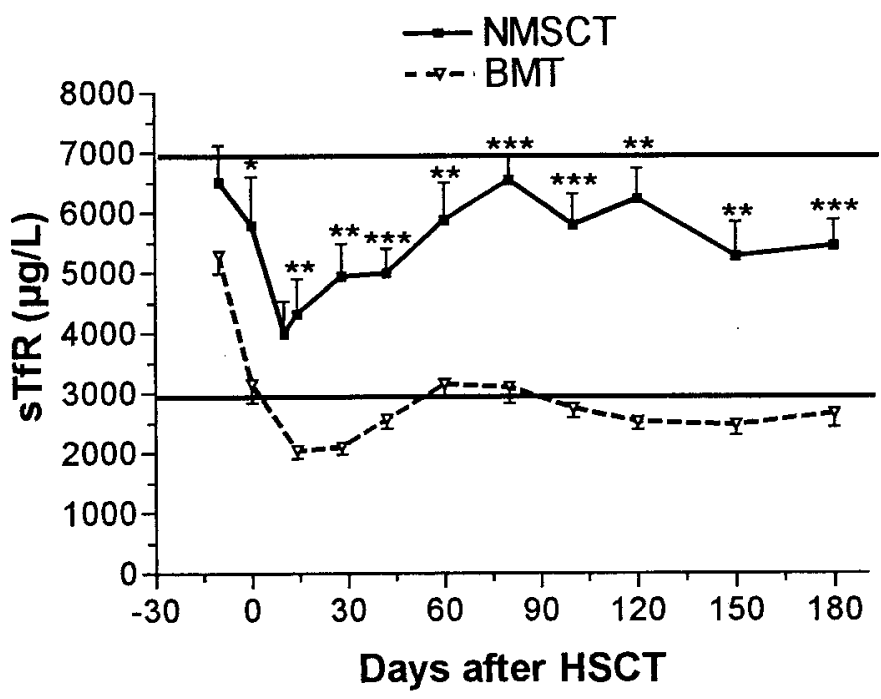

FIGURE 3. Erythropoietic activity, as assessed by soluble transferrin receptor (sTfR) levels (mean \pm SEM) after NMSCT, compared with conventional BMT. (horizontal lines) $95 \%$ confidence interval of $\mathbf{S T f R}$ in normal subjects. $P$ values are given for comparisons between the two groups: $* \boldsymbol{P}<0.05$, **P $\boldsymbol{P}<0.01, * * * \boldsymbol{P}<0.001$

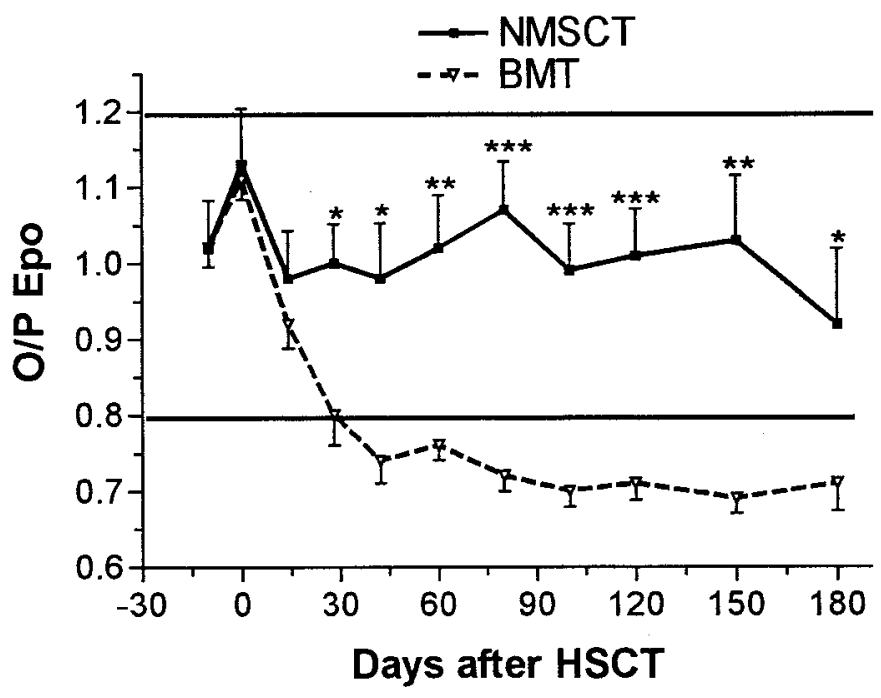

Figure 4. Epo production, as assessed by O/P Epo (mean \pm SEM), after NMSCT as compared with conventional BMT. (horizontal lines) 95\% confidence limits of observed-topredicted erythropoietin ratio (O/P Epo) in subjects with adequate Epo production. $P$ values are given for comparisons between the two groups: ${ }^{*} P<0.05,{ }^{*} * P<0.01, * * * P<0.001$.

$\mathrm{n}=31$ ). Although the number of observations after conventional PBSC transplant was too low for differences to reach statistical significance at any particular time point, pooled $\mathrm{O} / \mathrm{P}$ Epo values for the entire posttransplant course were significantly lower than in the NMSCT group $(P=0.0121)$.

\section{DISCUSSION}

Elevated serum Epo levels are observed transiently after intensive conditioning regimens without concomitant changes in $\mathrm{Hb}(18-27,35,36)$. The peak Epo values are 
usually observed 0 to 7 days after transplant, at the time of the nadir of erythropoietic activity. There is now substantial evidence that serum Epo levels partly depend on the rate of Epo use by Epo receptor-bearing erythroid precursors (27, 37). Therefore, severe myelosuppression following the conditioning regimen could disrupt the usual Epo degradation pathway and provoke a surge of serum Epo concentration through prolonged Epo life span (27). However, the NMSCT recipients in the current study received a much milder conditioning regimen and yet still experienced a significant drop in erythropoietic activity (Fig. 3), resulting in some decrease in $\mathrm{Hb}$ levels (Fig. 2). Although the level of erythropoiesis remained well within the normal range, the surge in serum Epo levels was quite similar to that observed after myeloablative conditioning (Fig. 4). Indeed, it has been suggested that such changes in serum Epo levels could relate to change in the rate of production rather than in the rate of use (38).

With marrow recovery after a myeloablative transplant, Epo levels progressively return to an appropriate range, and the duration of this correction phase inversely correlates with the speed of engraftment (27). This is consistent with increased Epo consumption by an expanding pool of erythroid precursors. However, animal experiments indicate that marrow accumulation of Epo is minimal, and that Epo life span is not significantly influenced by erythropoietic activity (39, 40). Indeed, experimental data suggest that variations in plasma Epo levels during periods of rapidly expanding erythropoiesis are the result of decreased production rather than enhanced use (38), but the precise mechanisms remain to be elucidated.

After marrow recovery, endogenous Epo remains appropriate for the degree of anemia in autologous transplant recipients $(19,20,22,23,25,26)$ but rapidly becomes inadequately low in patients receiving a myeloablative allogeneic transplant (19-21, 24-26). This translates into erythropoietic activity and $\mathrm{Hb}$ levels remaining quite low for several months (25). This defect in Epo production has been partly attributed to the use of CsA $(29,30)$, which does not affect the expression of the Epo gene but causes an inhibition of Epo secretion (30). However, other factors such as acute $\operatorname{GvHD}(20,24,25$, $28)$ or CMV infection $(20,28)$ have also been involved. We have recently shown that starting rHuEpo around day 35 after conventional allogeneic HSCT resulted in major responses in more than $90 \%$ of the patients (34), demonstrating that $\mathrm{rHuEpo}$ substitution at the time of marrow recovery can accelerate erythropoietic reconstitution that would otherwise remain impaired because Epo levels remain inadequate for prolonged periods of time.

Interestingly, our NMSCT recipients did not experience inappropriately low Epo levels for the degree of anemia nor the subsequent decrease in erythropoietic activity. Rather, Epo O/P ratios and sTfR levels were constantly well within the normal range. The reasons for this discrepancy with conventional transplants remain unclear. The use of PBSC instead of marrow as the source of stem cells cannot be incriminated because the control group of conventional PBSC transplants behaved similarly to the conventional BMT recipients. NMSCT recipients received CsA at least to day 120 after the transplant, and blood CsA levels were quite high. This could indicate that CsA is not the primary cause for the inappropriately low Epo levels observed after conventional transplant. Similarly, the rate of CMV reactivation in our
NMSCT patients (58\%) was comparable with that observed in our conventional BMT recipients (50\%) (25).

Acute GvHD has also been associated with the defect in Epo production. The incidence of acute GvHD was lower in our NMSCT patient (41\%) compared with our BMT group (64\%) (25). This is in accordance with the generally lower incidence and severity of acute GvHD observed after NMSCT (16). This relatively low incidence of acute GvHD may partly explain their appropriate levels of serum Epo. It has been suggested that the persistence of recipient hematopoietic or immune cells (mixed chimerism) after NMSCT could contribute to improve donor-versus-host tolerance (41). One could speculate that such tolerance toward host tissues would also apply to host Epo-producing cells either directly or through more limited production of inhibitory cytokines (42).

In conclusion, contrary to what is observed after conventional myeloablative HSCT, serum Epo levels remain adequate throughout the posttransplant course after NMSCT. These results suggest that the administration of rHuEpo could be less effective after NMSCT than after conventional allogeneic transplant.

\section{REFERENCES}

1. Thomas ED, Blume KG. Historical markers in the development of allogeneic hematopoietic cell transplantation. Biol Blood Marrow Transplant 1999; 5: 341 .

2. Appelbaum FR. Haematopoietic cell transplantation as immunotherapy. Nature 2001; 411: 385.

3. Barrett J, Childs R. The benefits of an alloresponse: graft-versus-tumor. J Hematother Stem Cell Res 2000; 9: 347.

4. Morecki S, Slavin S. Toward amplification of a graft-versus-leukemia effect while minimizing graft-versus-host disease. J Hematother Stem Cell Res 2000; 9: 355.

5. Baron F, Beguin Y. Adoptive immunotherapy with donor lymphocyte infusions after allogeneic HPC transplantation. Transfusion 2000; 40: 468-476.

6. Porter DL. The graft-versus-tumor potential of allogeneic cell therapy: an update on donor leukocyte infusions and nonmyeloablative allogeneic stem cell transplantation. J Hematother Stem Cell Res 2001; 10: 465.

7. Baron F, Beguin Y. Nonmyeloablative allogeneic hematopoietic stem cell transplantation. J Hematother Stem Cell Res. 2002; 11:243.

8. Baron F, Siquet J, Schaaf-Lafontaine N, et al. Pre-emptive immunotherapy with CD8-depleted donor lymphocytes after CD34-selected allogeneic peripheral blood stem cell transplantation. Haematologica 2002; 87: 78 .

9. McSweeney PA, Niederwieser D, Shizuru J, et al. Hematopoietic cell transplantation in older patients with hematologic malignancies: replacing high-dose cytotoxic therapy with graft-versus-tumor effects. Blood 2001; 97: 3390 .

10. Weissinger F, Sandmaier BM, Maloney DG, et al. Decreased transfusion requirements for patients receiving nonmyeloablative compared with conventional peripheral blood stem cell transplants from HLA-identical siblings. Blood 2001; 98: 3584.

11. Storb R, Yu C, Wagner JL, et al. Stable mixed hematopoietic chimerism in DLA-identical littermate dogs given sublethal total body irradiation before and pharmacological immunosuppression after marrow transplantation. Blood 1997; 89: 3048.

12. McSweeney PA, Storb R. Mixed chimerism: preclinical studies and clinical applications. Biol Blood Marrow Transplant 1999; 5: 192.

13. Zaucha JM, Zellmer E, Georges G, et al. G-CSF-mobilized peripheral blood mononuclear cells added to marrow facilitates engraftment in nonmyeloablated canine recipients: CD3 cells are required. Biol Blood Marrow Transplant 2001; 7: 613 .

14. Zaucha JM, Yu C, Zellmer E, et al. Effects of extending the duration of postgrafting immunosuppression and substituting granulocyte-colonystimulating factor-mobilized peripheral blood mononuclear cells for marrow in allogeneic engraftment in a nonmyeloablative canine transplantation model. Biol Blood Marrow Transplant 2001; 7: 513.

15. Zaucha JA, Yu C, Lothrop CD Jr, et al. Severe canine hereditary hemolytic anemia treated by nonmyeloablative marrow transplantation. Biol 
Blood Marrow Transplant 2001; 7: 14.

16. Baron $F$, Baudoux E, Frère $P$, et al. Nonmyeloablative stem cell transplantation (NMSCT) with CD8-depleted or CD34-selected PBSC. J Hematother Stem Cell Res 2002;11:301.

17. Beguin Y. A risk-benefit assessment of epoetin in the management of anaemia associated with cancer. Drug Saf 1998; 19: 269.

18. Abedi MR, Backman L, Bostrom L, et al. Markedly increased serum erythropoietin levels following conditioning for allogeneic bone marrow transplantation. Bone Marrow Transplant 1990; 6: 121.

19. Schapira L, Antin JH, Ransil BJ, et al. Serum erythropoietin levels in patients receiving intensive chemotherapy and radiotherapy. Blood 1990; 76: 2354.

20. Beguin Y, Clemons GK, Oris R, et al. Circulating erythropoietin levels after bone marrow transplantation: inappropriate response to anemia in allogeneic transplants. Blood 1991; 77: 868.

21. Bosi A, Vannucchi AM, Grossi A, et al. Inadequate erythropoietin production in allogeneic bone marrow transplant patients. Haematologica 1991; 76: 280.

22. Bosi A, Vannucchi AM, Grossi A, et al. Serum erythropoietin levels in patients undergoing autologous bone marrow transplantation. Bone Marrow Transplant 1991; 7: 421.

23. Lazarus HM, Goodnough LT, Goldwasser E, et al. Serum erythropoietin levels and blood component therapy after autologous bone marrow transplantation: implications for erythropoietin therapy in this setting. Bone Marrow Transplant 1992; 10: 71.

24. Miller CB, Jones RJ, Zahurak ML, et al. Impaired erythropoietin response to anemia after bone marrow transplantation. Blood 1992; 80: 2677.

25. Beguin Y, Oris R, Fillet G. Dynamics of erythropoietic recovery following bone marrow transplantation: role of marrow proliferative capacity and erythropoietin production in autologous versus allogeneic transplants. Bone Marrow Transplant 1993; 11: 285.

26. Davies SV, Fegan CD, Kendall R, et al. Serum erythropoietin during autologous bone marrow transplantation: relationship to measures of erythroid activity. Clin Lab Haematol 1995; 17: 139.

27. Beguin Y, Baron F, Fillet G. Influence of marrow activity on serum erythropoietin levels after autologous hematopoietic stem cell transplantation. Haematologica 1998; 83: 1076.

28. Ireland RM, Atkinson K, Concannon A, et al. Serum erythropoietin changes in autologous and allogeneic bone marrow transplant patients. Br J Haematol 1990; 76: 128.

29. Vannucchi AM, Grossi A, Bosi A, et al. Impaired erythropoietin production in mice treated with cyclosporin A. Blood 1991; 78: 1615.

30. Vannucchi AM, Grossi A, Bosi A, et al. Effects of cyclosporin A on eryth- ropoietin production by the human Hep3B hepatoma cell line. Blood 1993; 82: 978

31. Beguin Y, Clemons GK, Pootrakul P, et al. Quantitative assessment of erythropoiesis and functional classification of anemia based on measurements of serum transferrin receptor and erythropoietin. Blood 1993; 81: 1067.

32. Locatelli F, Zecca M, Pedrazzoli P, et al. Use of recombinant human erythropoietin after bone marrow transplantation in pediatric patients with acute leukemia: effect on erythroid repopulation in autologous versus allogeneic transplants. Bone Marrow Transplant 1994; 13: 403.

33. Link H, Boogaerts MA, Fauser AA, et al. A controlled trial of recombinan human erythropoietin after bone marrow transplantation. Blood 1994; 84: 3327.

34. Baron F, Sautois B, Baudoux E, et al. Optimization of recombinant human erythropoietin (rHuEpo) after allogeneic hematopoietic stem cell transplantation (HSCT). Exp Hematol 2002;30:546.

35. Birgegard G, Wide L, Simonsson B. Marked erythropoietin increase before fall in $\mathrm{Hb}$ after treatment with cytostatic drugs suggests mechanism other than anaemia for stimulation. Br J Haematol 1989; 72: 462.

36. Beguin Y, Collignon J, Laurent C, et al. Spontaneous complete remission and recovery of donor haemopoiesis without GVHD after relapse and apparent marrow graft rejection in poor-prognosis myelodysplastic syndrome. Br J Haematol 1996; 94: 507.

37. Cazzola M, Guarnone R, Cerani P, et al. Red blood cell precursor mass as an independent determinant of serum erythropoietin level. Blood 1998; 91: 2139

38. Lezon C, Alippi RM, Barcelo AC, et al. Depression of stimulated erythropoietin production in mice with enhanced erythropoiesis. Haematologica 1995; 80: 491

39. Piroso E, Erslev AJ, Flaharty KK, et al. Erythropoietin life span in rats with hypoplastic and hyperplastic bone marrows. Am J Hematol 1991; 36: 105.

40. Naets JP, Wittek M. Effect of erythroid hyperplasia on utilization of erythropoietin. Nature 1965; 206: 726

41. Pelot MR, Pearson DA, Swenson K, et al. Lymphohematopoietic graftversus-host reactions can be induced without graft-versus-host disease in murine mixed chimeras established with a cyclophosphamide-based non-myeloablative conditioning regimen. Biol Blood Marrow Transplant 1999; 5: 133 .

42. Hellwig-Burgel T, Rutkowski K, Metzen E, et al. Interleukin-1beta and tumor necrosis factor-alpha stimulate DNA binding of hypoxia-inducible factor-1. Blood 1999; 94: 1561. 